\title{
ANALISIS IMPLEMENTASI FREQUENCY DIVERSITY TERHADAP NILAI AVAILABILITY SYSTEM PADA WILAYAH URBAN DAN RURAL
}

\section{ANALYSIS OF FREQUENCY DIVERSITY IMPLEMENTATION OF AVAILABILITY SYSTEM VALUE IN URBAN AND RURAL REGION}

\author{
Anggi Shabrina $1^{1}$, EkaWahyudi $2^{2}$, Solichah Larasati $3^{3}$ \\ ${ }^{1,2,3}$ Program Studi S1 Teknik Telekomunikasi, Fakultas Teknik Telekomunikasi \& Elektro, Institut \\ Teknologi Telkom Purwokerto \\ $\underline{1} \underline{16101045 @ \text { ittelkom-pwt.ac.id 1, }} \underline{2} \underline{0617117601 @ \text { ittelkom-pwt.ac.id 2, }}$ 3 laras@ittelkom-pwt.ac.id
}

\begin{abstract}
Abstrak
Salah satu media transmisi yang banyak digunakan yaitu media transmisi menggunakan gelombang mikro. Gelombang mikro masih dibutuhkan saat ini karena tidak semua lokasi diizinkan untuk pergelaran jaringan menggunakan kabel, selain itu pengaruh terhadap bencana alam kecil, dan lebih praktis diimplementasikan pada wilayah urban maupun rural. Namun dalam penggunaan transmisi gelombang mikro terdapat kendala-kendala yang dapat menyebabkan proses transmisi mengalami gangguan dalam proses penyampaian informasi. Salah satu kendala yang mempengaruhi transmisi gelombang radio yaitu adanya efek fading yang menyebabkan turunnya daya terima dan rusaknya kualitas transmisi. Oleh sebab itu, perlu dilakukan proses optimasi untuk meningkatkan availability sistem komunikasi gelombang mikro. Penggunaan teknik diversity yang dapat meningkatkan nilai kehandalan sistem. Pada penelitian ini teknik diversity yang digunakan yaitu frequency diversity. Hasil dari simulasi perancangan jaringan transmisi gelombang mikro pada penelitian ini mendapatkan nilai kehandalan sistem sebelum menggunakan teknik diversity yaitu sebesar 99,99331\%. Setelah menggunakan teknik frequency diversity didapatkan hasil sebesar 99,99978\%. Hasil akhir simulasi ini sesuai dengan yang diharapkan dengan adanya penerapan teknik frequency diversity akan mengoptimalkan layanan kepada penggunan dengan tingkat kehandalan sistem sebesar $0,00647 \%$ lebih optimal.
\end{abstract}

Kata kunci: Diversity, frequency diversity, gelombang mikro, availability.

\begin{abstract}
One of the widely used transmission media is transmission media using microwave. Microwaves are still needed today as not all locations allow for network performances using cables, in addition to the influence of small natural disasters, and are more practical to implement in urban and rural areas. But in the use of micro wave transmission there are constraints that can cause the transmission process to experience interference in the process of conveying information. One obstacle that affects transmission of radio waves is the presence of fading effect that causes the decline in the receiving power and damage transmission quality. Therefore, the optimization process is necessary to increase the availability of the microwave communication system. The use of a diversity technique can increase the value of system reliability. In this research the diversity technique used is frequency diversity. The result of the design simulation of microwave transmission network in this study obtained the value of system reliability before using the diversity technique of $99.99331 \%$. After using the frequency diversity technique obtained the result of $99.99978 \%$. The final result of this simulation is as expected by the application of frequency diversity technique will optimize service to users with a system reliability level of $0.00647 \%$ more optimal.
\end{abstract}

Keywords: Diversity, frequency diversity, microwaves, availability. 


\section{PENDAHULUAN}

Menurut Badan Pusat Statistik Indonesia, jumlah penduduk Indonesia sudah mencapai 264 juta. Bertambahnya jumlah penduduk, maka bertambah pula pengguna jaringan telekomunikasi di Indonesia. Perkembangan pengguna ini juga mempengaruhi perkembangan teknologi telekomunikasi di Indonesia. Seiring dengan bertambahnya jumlah pengguna, maka pelayanan jaringan telekomunikasi juga perlu ditingkatkan. Pada sistem komunikasi saluran jaringan transmisi sangat memegang peranan penting dalam menyalurkan data dari sumber ke tujuan. Dalam proses transmisi ini media yang digunakan sangat banyak antara lain media melalui kabel maupun tanpa kabel[1].

Mengingat di Indonesia dengan kondisi geografis terdiri dari perairan, gunung, dan perbukitan maka diperlukannya teknologi tanpa kabel. Hal ini mampu diimplementasikan pada wilayah yang tidak dapat dijangkau menggunakan teknologi wireline. Teknologi ini disebut dengan jaringan komunikasi gelombang mikro, dengan sistem transmisi menggunakan microwave dan antena sebagai alat untuk memancarkan sinyal agar dapat saling berkomunikasi. Dalam proses terjadinya sistem komunikasi ini secara point to point terdapat dua buah antena sebagai transmitter (Tx) berfungsi sebagai media pengirim sinyal dan receiver $(\mathrm{Rx})$ yang berfungsi sebagai media penerima sinyal.

Media transmisi gelombang mikro merupakan media transmisi tanpa kabel yang banyak dipilih karena proses perambatannya relatif cepat, serta instalasi yang relatif lebih mudah. Sedangkan dengan media transmisi kabel sebagai contoh kabel optik, instalasi yang lebih sulit serta biaya yang lebih tinggi dibandingkan dengan media transmisi gelombang mikro. Namun dalam penggunaan transmisi gelombang mikro tidak terlepas dengan kendala-kendala yang dapat menyebabkan proses transmisi mengalami gangguan yang mengakibatkan proses dalam penyampaian informasi terganggu.

Adapun salah satu hal yang dapat mempengaruhi transmisi gelombang radio yaitu adanya fading. Fading merupakan fenomena turun naiknya sinyal yang menyebabkan turunnya daya terima dan rusaknya kualitas transmisi. Maka dari itu haruslah adanya nilai unjukkerja atau nilai kehandalan dalam sistem jaringan tersebut agar mendapatkan kondisi sistem secara optimal. Pada ukuran kehandalan suatu sistem disebut dengan availability. Dari nilai availability dapat diketahui apakah sistem dalam keadaan optimal maupun tidak. Secara umum nilai dari kehandalan sistem haruslah $100 \%$, namun dengan adanya loss dalam sistem tidak mungkin terpenuhi.

Oleh sebab itu, optimasi perlu dilakukan untuk meningkatkan availability sistem komunikasi microwave. Berdasarkan penelitian sebelumnya diketahui hasil dengan menggunakan teknik diversity dapat meningkatkan nilai kehandalan sistem pada jaringan komunikasi tersebut. Beberapa teknik diversity yaitu space diversity dengan penggunaan dua antena pada sisi pengirim maupun penerima menggunakan satu frekuensi kerja. Sedangkan, pada teknik frequency diversity dengan penggunaan satu antena pada sisi pengirim dan penerima, namun menggunakan dua frekuensi kerja.

Dalam penelitian ini, penulis menggunakan teknik frequency diveristy pada lokasi penelitian di wilayah urban dan rural sebagai solusi terbaik. Dengan pemilihan teknik ini di dasari agar penggunaan dengan dua frekuensi kerja dapat meminimalkan cost yang digunakan. Hal ini mampu mengoptimalkan layanan kepada pengguna agar nilai kehandalan sistem yang didapatkan baik. Dengan latar belakang ini penulis mengangkat tema dengan judul "ANALISIS IMPLEMENTASI FREQUENCY DIVERSITY TERHADAP NILAI A VAILABILITY SYSTEM PADA WILAYAH URBAN DAN RURAL". Adapun maksud dan tujuannya yaitu untuk merencanakan sistem komunikasi radio gelombang mikro digital point to point yang memenuhi syarat Line of Sight (LOS) dan analisis kehandalan sistem berdasarkan metode frequency diversity. 


\section{DASAR TEORI}

\subsection{Sistem Komunikasi Gelombang Mikro}

Sistem komunikasi radio gelombang mikro adalah sistem komunikasi yang dapat mengirimkan informasi dari satu lokasi pengirim ke lokasi penerima tanpa terganggu kondisi daratan. Komunikasi berupa suara, video, dan data dikirimkan melalui udara bebas (air interface) pada range frekuensi $2 \mathrm{GHz}$ sampai $24 \mathrm{GHz}$, berdasarkan standar yang direkomendasikkan oleh Committee Consultative International on Radio (CCIR)[2].

Sistem komunikasi microwave terdiri dari 2 bagian utama yaitu pemancar (transmitter) dan penerima (receiver). Dalam perjalanannya dari antena pemancar ke antena penerima, sinyal radio microwave melalui berbagai rintangan dengan mekanisme perambatan dasar. Mekanisme perambatan tersebut adalah Line-of-sight (LOS) yang merupakan lintasan propagasi gelombang radio berdasarkan garis pandang manusia. Ini berarti bahwa antara antena pemancar dengan antena penerima tidak boleh ada penghalang (obstacle) yang menghalangi lintasan propagasi seperti pada Gambar 2.1.

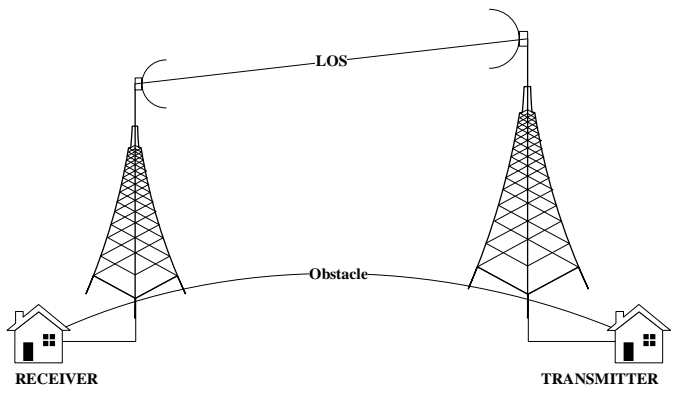

Gambar 2.1 Propagasi LOS[3]

Baik stasiun pemancar maupun penerima yang digunakan dalam jaringan harus ditempatkan di tempat yang tinggi, atau pada menara yang tinggi agar diperoleh daerah propagasi LOS yang maksimum. Sehingga ketika propagasi LOS maksimum akan diperoleh lintasan propagasi langsung (direct signal path). Propagasi LOS untuk radio gelombang mikro menggunakan sinyal gelombang radio atau Radio Frequency (RF) yang merupakan gelombang elektromagnetik[4].

Komunikasi radio microwave biasanya digunakan untuk sistem komunikasi satelit maupun sistem komunikasi terrestrial yang dirambatkan melalui atmosfer, sehingga kondisi atmosfer akan sangat mempengaruhi energi perambatan gelombangnya. Fluktuasi penurunan energi berkas gelombang akibat atmosfer ini disebut dengan fading[5].

\subsection{Klasifikasi Link Microwave}

Komunikasi radio microwave digunakan dalam sistem komunikasi seluler sebagai jalur transmisi yang menghubungkan satu MSC dengan MSC yang lain yang dalam satu jaringannya, penghubung MSC dengan BSC, penghubung BSC dengan beberapa BTS, maupun antar BTS. Walaupun terdapat alternatif lain dengan menggunakan jalur transmisi kabel serat optik, ataupun saluran wireline lainnya, jalur transmisi microwave masih lebih sering digunakan. Pada umumnya link microwave beroperasi pada range frekuensi $2 \mathrm{GHz}$ sampai $58 \mathrm{GHz}$. Berdasarkan range frekuensi kerjanya, link microwave dapat diklasifikasikan menjadi tiga kategori yaitu short haul, medium haul, dan long haul [6]. Dapat dilihat pada Tabel 2.1.

Tabel 2.1 Band frekuensi transmisi gelombang mikro[6]

\begin{tabular}{|c|c|c|}
\hline Range Frekuensi & Band Frekuensi & Jangkauan Maksimum \\
\hline & $23 \mathrm{GHz}$ & $18 \mathrm{~km}$ \\
\hline
\end{tabular}


Jurnal Elektro Telekomunikasi Terapan Juli 2020

\begin{tabular}{|c|c|c|}
\hline \multirow{4}{*}{$\begin{array}{c}\text { Short Haul }(23 \mathrm{GHz} \\
-58 \mathrm{GHz})\end{array}$} & $26 \mathrm{GHz}$ & $15 \mathrm{~km}$ \\
\cline { 2 - 3 } & $27 \mathrm{GHz}$ & $15 \mathrm{~km}$ \\
\cline { 2 - 3 } & $38 \mathrm{GHz}$ & $10 \mathrm{~km}$ \\
\cline { 2 - 3 } & $55 \mathrm{GHz}$ & $<10 \mathrm{~km}$ \\
\hline Range Frekuensi & Band Frekuensi & Jangkauan Maksimum \\
\hline \multirow{2}{*}{$\begin{array}{c}\text { Medium Haul }(13 \\
\mathrm{GHz}-18 \mathrm{GHz})\end{array}$} & $13 \mathrm{GHz}$ & $40 \mathrm{~km}$ \\
\cline { 2 - 3 } & $15 \mathrm{GHz}$ & $35 \mathrm{~km}$ \\
\cline { 2 - 3 } Long Haul $(2 \mathrm{GHz}-$ & $18 \mathrm{GHz}$ & $20 \mathrm{~km}$ \\
\cline { 2 - 3 } $10 \mathrm{GHz})$ & $2 \mathrm{GHz}$ & $80 \mathrm{~km}$ \\
\cline { 2 - 3 } & $7 \mathrm{GHz}$ & $50 \mathrm{~km}$ \\
\cline { 2 - 3 } & $10 \mathrm{GHz}$ & $45 \mathrm{~km}$ \\
\hline
\end{tabular}

Pada Tabel 2.1, ada beberapa range frekuensi yang digunakan dan hal ini disesuaikan dengan band frekuensi yang akan mempengaruhi jangkauan maksimum pada band frekuensi yang digunakan, dapat dicontohkan untuk band frekuensi yang penulis gunakan yaitu sebesar $8 \mathrm{GHz}$ yang mana hal ini dapat menjangkau jarak maksimum sejauh $50 \mathrm{~km}$.

\subsection{Penanggulangan Fading}

Terdapat banyak pengaruh redaman dan fading pada berkas gelombang mikro, oleh karena itu perlu diberikan suatu solusi untuk mengatasinya yaitu dengan peragaman (diversity). Diversity adalah suatu teknologi yang diterapkan pada penerimaan sistem komunikasi yang pada dasarnya untuk mengatasi pengaruh fading yang terjadi pada lintasan jalur komunikasi microwave dan operasi sistem ini dilakukan oleh dua atau lebih pada sistem secara bersamaan untuk meningkatkan kuali tas sinyal yang diterima. Contoh teknik diversity yaitu space diversity dan frequency diversity[2]. Teknik ini dapat digambarkan sebagai perangkat yang redundancy, alternatif atau jalur jaringan cadangan yang digunakan untuk meningkatkan ketersediaan jaringan. Ini memungkinkan jalur untuk dihubungkan bahkan jika link pada jaringan terputus, tanpa mempengaruhi konektivitas perangkat di jalur tersebut.

\subsubsection{Frequency Diversity}

Frequency diversity seperti yang ditunjukan pada Gambar 2.2 merupakan sistem yang mengoperasikan dua frekuensi gelombang mikro pada satu antena baik itu di pemancar maupun penerima. Informasi yang dikirimkan secara simultan dikirimkan kedua transmitter yang beroperasi pada frekuensi yang berbeda kemudian diteruskan ke satu antena pemancar[2]. Pada antena penerima akan dikumpulkan informasi dan memisahkannya menjadi dua sinyal.

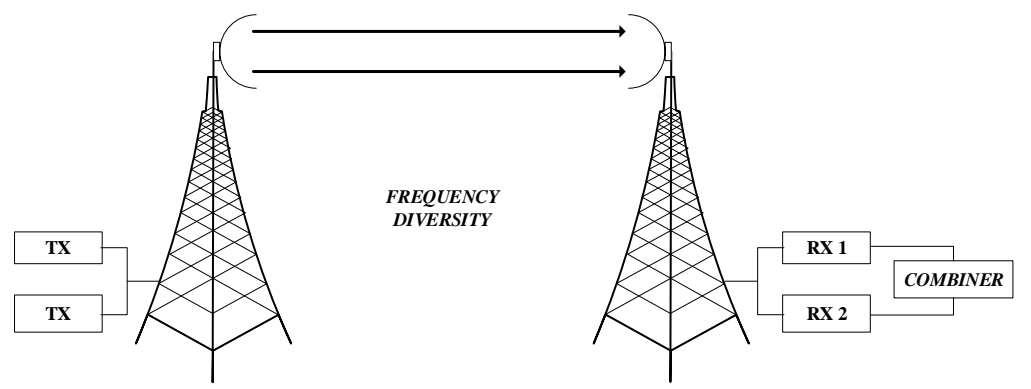

Gambar 2.2 Sistem Frequency Diversity[3] 


\subsection{Perhitungan Frequency Diversity}

Pada teknik Frequency Diversity sistem yang mengoperasikan dua frekuensi gelombang mikro pada satu antena baik itu di pemancar maupun penerima. Informasi yang dikirimkan secara simultan oleh kedua transmitter yang beroperasi pada frekuensi yang berbeda kemudian diteruskan ke satu antena pemancar. Pada antena penerima akan dikumpulkan informasi dan memisahkannya menjadi dua sinyal. Perbedaan frekuensi $(\Delta \mathrm{f})$ anatara kedua frekuensi cukup $2 \%$ dan akan lebih baik jika berbeda $6 \%$ untuk menghindari terjadinya interferensi yang besar. Apabila dalam sistem transmisi menggunakan teknik frekuensi diversity untuk mengatasi fading, maka akan diperoleh faktor perbaikan ditunjukan Persamaan 2.1 [6]:

$$
I_{f d}=\frac{0.8 \times \Delta f}{f^{2} \times D} \times 10^{F M / 10}
$$

keterangan, $\Delta \mathrm{f}$ adalah perbedaan frekuensi diversity, jika persamaan di atas diubah kedalam desibel maka akan didapatkan Persamaan 2.2 [6]:

$$
\mathrm{I}_{\mathrm{fd}}=10 \log \Delta \mathrm{f}+20 \log f-10 \log \mathrm{D}+F M 0.9
$$

Setelah sistem mendapatkan perbaikan, maka didapatkan perbandingan fading margin dengan frekuensi diversity ditunjukan Persamaan 2.3 [6]:

$$
\mathrm{FM}=20 \log \mathrm{D}+5 \log (2.5 \times a \times b)+15 \log f-5 \log \text { UnAvpath }-5 \log \Delta f-29.5
$$

keterangan, $\Delta \mathrm{f}$ adalah perbedaan frekuensi yang digunakan dalam sistem transmisi yang menggunakan teknik frekuensi diversity, sedangkan $\mathrm{I}_{\mathrm{fd}}$ adalah faktor perbaikan setelah menggunakan teknik frekuensi diversity $(\mathrm{dB})$.

\subsection{Perhitungan Link Budget}

\section{Gain Antena}

Parameter pengukur kemampuan antena untuk mengirimkan gelombang yang diinginkan ke arah tujuan. Pada antena parabola, efisiensi tidak mencapai $100 \%$ karena beberapa daya hilang. Secara komersial, efisiensi antena parabola antara 50\% hingga 70\%. Besarnya nilai gain dapat dicari menggunakan Persamaan 2.8 [18].

$G=20 \log f+20 \log d+10 \log \eta+20,4$

keterangan,

$\mathrm{G}$ adalah gain atau penguatan antena (dBi)

$\mathrm{d}$ adalah diameter antena $(\mathrm{m})$

$\mathrm{f}$ adalah frekuensi antena $(\mathrm{GHz})$

$\eta$ adalah efisiensi antena $(50 \%-70 \%)$

2. $\quad$ Free Space Loss (FSL)

Free Space Loss adalah redaman yang sepanjang ruang antara antena pemancar dan penerima. Pada ruang ini tidak di bolehkan adanya penghalang, karena transmisinya sendiri berkarakter LOS. Besarnya FSL dapat dihitung dengan Persamaan 2.9 [18].

$\mathrm{FSL}=92,45+20 \log (\mathrm{fGHz})+20 \log (\mathrm{DKm})$

keterangan,

FSL adalah Free Space Loss (dB)

$\mathrm{F}$ adalah frekuensi $(\mathrm{GHz})$

$\mathrm{D}$ adalah jarak antara antena pemancar dan penerima $(\mathrm{km})$

3. Effective Isotropic Radiated Power (EIRP) 
EIRP merupakan daya maksimum gelombang sinyal mikro yang keluar dari antena pemancar atau untuk menunjukan nilai efektif daya yang dipancarkan antena pemancar, dalam arti lain daya tersebut sudah mengalami penguatan dapat dituliskan seperti Persamaan 2.10 [7].

$\mathrm{EIRP}=P_{T x}+G_{\text {antena }}-L_{T x}$

keterangan,

EIRP adalah Effective Isotropic Radiated Power $(\mathrm{dBm})$

$\mathrm{P}_{\mathrm{Tx}}$ adalah daya pancar $(\mathrm{dBm})$

$\mathrm{G}_{\text {antena adalah gain antenna }(\mathrm{dBi})}$

$\mathrm{L}_{\mathrm{Tx}}$ adalah transmitter loss $(\mathrm{dB})$

4. Isotropic Receive Level (IRL)

Besaran nilai IRL harus didapatkan terlebih dahulu untuk mendapatkan nilai daya terima pada antena penerima. Besar nilai IRL didapatkan dari Persamaan 2.11 [7].

IRL $=$ EIRP - FSL

keterangan,

IRL adalah Isotropic Received Level (dBW)

EIRP adalah Effective Isotropic Radiated Power (dBW)

FSL adalah Free Space Loss (dB)

5. Receive Signal Level (RSL)

Rugi-rugi pada jalur di sisi antena penerima serta gain pada antena penerima memperoleh besar nilai RSL. Nilai RSL pada piranti pengolah decoding dapat dihitung dengan menggunakan Persamaan 2.12[7].

$\mathrm{RSL}=\mathrm{IRL}-\mathrm{G}_{\mathrm{Rx}}-\mathrm{L}_{\mathrm{Rx}}$

keterangan,

RSL adalah Received Signal Level (dBm)

IRL adalah Isotropic Received Level ( $\mathrm{dBm})$

$G_{R x}$ adalah Gain Antenna $R x(\mathrm{dBi})$

$L_{R x}$ adalah Receiver Loss $(\mathrm{dB})$

6. Hoploss

Hoploss adalah perbedaan atau selisih antara gain dan loss pada link microwave Besarnya Hoploss dinyatakan dengan Persamaan 2.13[7].

$L_{h}=F S L+L_{e x}+L_{A t m}-\left(G_{T x}+G_{R x}\right)$

keterangan,

$L_{h}$ adalah hoploss $(\mathrm{dB})$

FSL adalah Free Space Loss (dB)

$L_{e x}$ adalah loss tambahan $(\mathrm{dB})$; loss sisi tx-rx tanpa pengaruh atmosfer

$L_{A t m}$ adalah atmosphere loss $(\mathrm{dB})$

$G_{T x}$ adalah gain receive antenna $(\mathrm{dBi})$

$G_{R x}$ adalah gain transmit antenna $(\mathrm{dBi})$

7. Fading Margin

Untuk mengetahui cadangan daya pada teknik frequency diversity dapat menggunakan

Persamaan 2.14 di bawah ini.

$\mathrm{FM}=30 \log \mathrm{D}+10 \log (a \times b \times 2,5 \times f)-10 \log \mathrm{UnAv}_{\text {Path }}-60-\mathrm{I}_{\mathrm{fd}}$

keterangan,

FM adalah Fading Margin (dB)

$\mathrm{D}$ adalah panjang lintasan $(\mathrm{km})$

F adalah frekuensi $(\mathrm{GHz})$ 
$a$ adalah faktor kekasaran bumi, dengan parameter nilai 1 ialah daerah kekasaran rata-rata, dataran, dengan parameter nilai 4 ialah daerah halus, laut, danau,dan gurun, sedangkan dengan parameter nilai $1 / 4$ ialah merupakan pegunungan dan dataran tinggi.

$b$ adalah faktor iklim, dengan parameter nilai $1 / 4$ ialah daerah normal, 1/8 yaitu daerah pegunungan (sangat kering), nilai $1 / 2$ berupa daerah panas dan lembab namun dalam perancangan menggunakan kondisi terburuk yaitu, b dengan nilai 1 .

8. Availability

Metode Vigants-Barnet menggunaan persamaan antara $C$-factor dan effective fade margin untuk menghitung unAvailability. Persamaan tersebut dapat ditunjukan pada Persamaan 2.15[7].

$P=6 \times 10^{-7} \times C \times f \times D^{3} \times 10^{\frac{-F M}{10}}$

keterangan,

$P$ adalah unAvailability

$C$ adalah $C$ factor

$f$ adalah frekuensi $(\mathrm{GHz})$

$D$ adalah panjang lintasan $(\mathrm{km})$

FM adalah fading margin $(\mathrm{dB})$

Maka Availability dapat dinyatakan dengan Persamaan 2.16[7]:

$A v_{\text {path }}=(1-P) \times 100 \%$

keterangan, $P$ adalah unAvailability system sedangkan $\mathrm{Av}_{\text {path }}$ adalah Availability System.

\subsection{Pathloss}

PathLoss versi 5 merupakan perangkat lunak (software) untuk perancangan jaringan komunikasi radio microwave yang digunakan oleh sebagian besar perencana jaringan. Aplikasi ini dapat menampilkan simulasi yang cukup akurat dalam hal perangkat dan lingkungan dimana jaringan radio akan diterapkan. Agar jaringan radio dapat disimulasikan dengan sempurna, maka diperlukanlah beberapa data atau file pendukung yang berisi spesifikasi perangkat beserta lingkungannya. Data file yang diperlukan diantaranya:

1. Frequency Plan

File Frequency Plan ini berisi daftar frekuensi berlisensi yang dimiliki oleh berbagai vendor. Setiap vendor mempunyai daftar frekuensi yang berbeda sesuai dengan lisensi yang dibeli.

2. Microwave Antenna Data Files (MAS)

File MAS ini merupakan representasi karakteristik antena yang diproduksi oleh vendor.

3. Radio Models Data Files (MRS)

Sedangkan file MRS berisi implementasi radio yang sesuai dengan file MAS.

4. SRTM/Data Geografis.

SRTM berisi data topografi yang dibuat oleh NASA, file ini juga dapat diunduh secara bebas di internet. Jika empat data file diatas sudah lengkap dimiliki, maka simulasi link budget pun sudah dapat dibuat[8].

\section{PEMBAHASAN}

Pada sub bab ini akan membahas tentang perbandingan perhitungan link budget berdasarkan hasil report simulasi menggunakan teknik non-diversity dengan teknik frequency diversity menggunakan perangkat lunak simulasi Pathloss 5.0. Hasil perbandingan kedua kondisi tersebut 
dengan simulasi Pathloss 5.0 akan ditampilkan pada Tabel 3.1 di BTS Telaga Pulang (Rural) dan BTS Sembuluh (Urban) hasil perbandingan dapat diamati dibawah ini.

Tabel 3.1 Hasil perbandingan report simulasi Pathloss 5.0 BTS Telaga Pulang (Rural) dan B TS Sembuluh (Urban)

\begin{tabular}{|c|c|c|c|c|c|}
\hline \multicolumn{6}{|c|}{ BTS Telaga Pulang (Rural) - BTS Sembuluh (Urban) } \\
\hline Parameter & Standar & Non FD & FD $6 \%$ & $\begin{array}{c}\text { Selisih Non } \\
\text { FD \& FD }\end{array}$ & Keterangan \\
\hline Gain Antenna (dBi) & 40,8 & 40,40 & 40,40 & 0 & Sama baik \\
\hline Free Space Loss $(\mathrm{dB})$ & 135,98 & 136,00 & 136,00 & 0 & Sama baik \\
\hline $\operatorname{EIRP}(\mathrm{dBm})$ & 64 & $\begin{array}{c}63,88 \& \\
63,19\end{array}$ & $\begin{array}{c}63,88 \& \\
63,19\end{array}$ & 0 & Sama baik \\
\hline$R S L(d B m)$ & $-69,00$ & $-39,13$ & $-39,13$ & 0 & Sama baik \\
\hline Hoploss $(\mathrm{dB})$ & 95,6 & 69,13 & 69,13 & 0 & Sama baik \\
\hline $\begin{array}{l}\text { Dispersive Fade Margin } \\
(d B)\end{array}$ & 30 & 46,40 & 46,40 & 0 & Sama baik \\
\hline $\begin{array}{l}\text { Effective Fade Margin } \\
\qquad(d B)\end{array}$ & 30 & 29,78 & 29,78 & 0 & Sama baik \\
\hline Availability (\%) & $\begin{array}{c}99,9958- \\
99,9975\end{array}$ & 99,99331 & 99,99978 & 0,00647 & $\begin{array}{c}\text { Frequency } \\
\text { diversity } \\
\text { lebih baik }\end{array}$ \\
\hline
\end{tabular}

Dapat diketahui hasil perbandingan perhitungan link budget pada BTS Telaga Pulang (Rural) dengan BTS Sembuluh (Urban) menggunakan software simulasi Pathloss 5.0, dapat diamati hasil kehandalan sistem lebih baik setelah menggunakan teknik frequency diversity hal ini di dasari berdasarkan Tabel 3.1. Pada BTS Telaga Pulang (Rural) dan BTS Sembuluh (Urban) diperoleh nilai availability dari hasil simulasi Pathloss 5.0 sebelum menggunakan frequency diversity sebesar 99,99331\% lalu setelah ditambahkan frequency diversity dengan menggunakan frekuensi kerja yang sama yaitu $8 \mathrm{GHz}$ dengan inputan channel ID pada Pathloss 5.0, yaitu channel ID 6\%h (8841,662 MHz) untuk BTS Telaga Pulang (Rural) dan channel ID 6\%1 (8690,048 MHz) untuk BTS Sembuluh (Urban). Dengan perbedaan frekuensi atau frequency diversity yang digunakan adalah $6 \%$ dari frekuensi kerja sebesar $8 \mathrm{GHz}$ dengan inputan channel ID pada Pathloss 5.0 didapatkan nilai availability setelah frequency diversity sebesar 99,99978\%.

\section{KESIMPULAN}

Dapat disimpulkan hasil perbandingan jaringan transmisi radio gelombang mikro pada lokasi BTS Telaga Pulang (Rural) dan Sembuluh (Urban) menggunakan teknik frequency diversity menghasilkan perbaikan transmisi yang lebih optimal daripada jaringan transmisi menggunakan teknik non-diversity dengan nilai kehandalan sistem meningkat sebesar $0,00647 \%$. Hal ini didukung juga dengan nilai RSL sebesar -39,13 dBm yang akan memaksimalkan optimasi sinyal, dimana nilai RSL ini sudah mencakup nilai minimal Rx Threshold Level dengan nilai sebesar $-69,00 \mathrm{dBm}$. Berdasarkan ITU nilai RSL dengan rentang $\leq-50 \mathrm{dBm}$ sampai dengan $-88 \mathrm{dBm}$ dikategorikan cukup baik.

Untuk report hasil simulasi menggunakan software Pathloss 5.0 didapatkan nilai kehandalan sistem sebesar 99,99331\% dengan teknik non-diversity, sedangkan nilai kehandalan sistem dengan teknik frequency diversity didapatkan hasil sebesar 99,99978\%. Berdasarkan standar ITU-R G.827 
dan ITU-R F.1703 dengan rentang nilai availability 99,9958\% sampai dengan 99,9975\% maka nilai availability dengan teknik frequency diversity lebih baik daripada tanpa menggunakan teknik diversity pada lokasi BTS Telaga Pulang (Rural) dan Sembuluh (Urban), dengan peningkatan nilai availability ini dipengaruhi oleh nilai unavailability yang kecil dan juga nilai improvement factor frequency diversity (faktor perbaikan) yaitu adanya selisih frekuensi yang digunakan antara teknik non-diversity dengan teknik frequency diversity.

\section{DAFTAR PUSTAKA}

[1] O. I. Zuherry, Perancangan Jaringan Transmisi Microwave Menggunakan Passive Repeater Back To Back dan Double Flat Reflector Menggunakan Pathloss 5.0, J. Telecommun. Electron. Control Eng., vol. 1, no. 1, hal. 53-62.

[2] A. Hikmaturrokhman, Diktat Kuliah Gelombang Mikro. Purwokerto. Akatel Sandhy Putra, 2007.

[3] A. Hikmaturrokhman, Alfin dan Wahyudin, Perancangan Jaringan Gelombang Mikro Menggunakan Pathloss 5.0, 1 ed. Yogyakarta: Pustaka Ilmu, 2018.

[4] O. R. Mariano, Design Software for Terrestrial Line-of-sight Communications Systems in the Philippines, Int. J. Res. $i$ Wirel. Syst., vol. 11, no. 1, hal. 24-30, 2012.

[5] R. L. Freeman, Telecommunication System Engineering, Fourth. New York: A John Wiley \& Sons, Ltd., 2004.

[6] A. Hikmaturokhman, Klasifikasi Link Microwave. Purwokerto: Akatel Sandhy Putra, 2012.

[7] A. S. Yuchintya, Analisis Pengaruh Passive Repeater Terhadap Nilai Availability Menggunakan Pathloss 5.0,Purwokerto, 2013.

[8] D. B. Liu, Optimasi Jaringan Microwave dengan Teknik Space Diversity Menggunakan Pathloss 5.0, 2017. 